\title{
Efficient miRNA Inhibitor Delivery with Graphene Oxide-Polyethylenimine to Inhibit Oral Squamous Cell Carcinoma
}

This article was published in the following Dove Press journal: International Journal of Nanomedicine

\author{
Lingling Ou' \\ Ting Sun' \\ Minyi Liu' \\ Ye Zhang' \\ Zhiying Zhou' \\ Xiaozhen Zhan' \\ Lihong Lu' \\ Qingtong Zhao' \\ Renfa Lai' \\ Longquan Shao (iD) ${ }^{2}$ \\ 'The First Affiliated Hospital of Jinan \\ University, Department of Stomatology, \\ Guangzhou 510632, People's Republic of \\ China; ${ }^{2}$ Stomatological Hospital of \\ Southern Medical University, Department \\ of Prosthodontics, Guangzhou 510260, \\ People's Republic of China
}

Background: MicroRNAs (miRNAs) are widely believed to be promising targets for oral squamous cell carcinoma (OSCC) gene therapy. miR-214 has been identified as a promoter of OSCC aggression and metastasis.

Methods: Graphene oxide-polyethylenimine (GO-PEI) complexes were prepared and loaded with a miRNA inhibitor at different N/P ratios. The transfection efficiency of GO-PEI-inhibitor was tested in Cal27 and SCC9 cells. Moreover, the tumor inhibition ability of GO-PEI-inhibitor was measured in an OSCC xenograft mouse model by intratumoral injection.

Results: Here, we show that a GO-PEI complex efficiently delivers a miR-214 inhibitor into OSCC cells and controls the intracellular release of the miR-214 inhibitor. These results indicate that the GO-PEI-miR-214 inhibitor complex efficiently inhibited cellular miR-214, resulting in a decrease in OSCC cell invasion and migration and an increase in cell apoptosis by targeting PTEN and p53. In the xenograft mouse model, the GO-PEI-miR-214 inhibitor complex significantly prevented tumor volume growth.

Conclusion: This study indicates that functionalized GO-PEI with low toxicity has promising potential for miRNA delivery for the treatment of OSCC.

Keywords: oral squamous cell carcinoma, GO-PEI, miR-214 inhibitor, gene therapy

\section{Introduction}

Oral squamous cell carcinoma (OSCC) is one of the six most common malignant cancers. $^{1,2}$ Although surgery, radiotherapy and chemotherapy techniques are continuously developing, the prognosis of OSCC is still rather poor. ${ }^{3,4}$ Recurrence and metastasis are commonly encountered. One important reason is that the anticancer drugs have low efficiency and are highly toxic to normal tissues. Recently, microRNAs (miRNAs) have been known as one of the most promising candidates for gene therapy, ${ }^{5,6}$ and gene drug delivery systems with nanodrug carriers have received widespread attention.

miRNAs are small noncoding RNAs that consist of 19-23 nucleotides and have important functions in various biological and pathological processes. ${ }^{7,8}$ The dysregulated expression of miRNAs has links with different kinds of tumors. ${ }^{9-11}$ Among a variety of miRNAs, miR-214 has been shown to promote tumor progression by regulating multiple signal pathways in OSCC. ${ }^{12-14}$ It has been reported that miR-214 knockdown inhibits tongue squamous cell carcinoma proliferation and promotes cell apoptosis. ${ }^{15}$ Therefore, miRNA-214 could serve as a potential therapeutic target in
The First Affiliated Hospital of Jinan University, No.613 West Huangpu

Avenue, Guangzhou 510632, People's

Republic of China

Email Prof.Dr.Lai@I63.com

Longquan Shao

Stomatological Hospital of Southern

Medical University, No. 366 South

Jiangnan Avenue, Guangzhou 510260,

People's Republic of China

Email shaolongquan@smu.edu.cn
International Journal of Nanomedicine 2020:15 I569-I583

1569

DovePress $f$ in $\boldsymbol{v}$

http://doi.org/10.2147यIN.S220057 
OSCC. Recently, antimiRs or antagomiRs were used to inhibit the function of miRNAs. ${ }^{16,17}$ AntagomiRs containing 2'-O-methyl-modified ribose sugars (2'-OMe) were the first miRNA inhibitors used in vivo. ${ }^{18}$ Although antagomiRs are more stable in vivo than anti-miRNA oligonucleotides (AMOs), the exact high dose needed to be used in tissues hindered their application. ${ }^{19}$ Great efforts have been made to deliver synthetic oligonucleotides effectively into cells or in vivo, and these efforts include the application of liposome formulations and nanocarriers. ${ }^{20}$ However, the results are far from satisfactory. Therefore, good vectors that can protect and deliver miRNAs effectively into cells are required for miRNA therapy.

Graphene oxide (GO) has become prominent in drug or gene delivery due to its excellent physicochemical properties, two-dimensional structure, high surface-to-volume ratio, strong absorption ability, etc. ${ }^{21,22} \mathrm{GO}$ efficiently loads aromatic chemotherapeutic drugs via $\pi-\pi$ interactions. ${ }^{23}$ It could potentially be used in gene vector systems for its outstanding properties. ${ }^{24}$ However, nucleic acids and GO both carry a negative charge, and the charge would cause electrostatic repulsion between them. ${ }^{25}$ To circumvent this issue, we designed a functionalized GO with positively charged polyetherimide (PEI). PEI has been known as one of the most powerful cationic gene delivery vectors because of its strong proton sponge effect. ${ }^{26,27}$ Abundant PEI can bind to GO and combine negative miRNA inhibitors to GO. In this study, PEI-functionalized GO was used for the delivery of a miR214 inhibitor into OSCC cells and xenograft tumors for antitumor therapy by inhibiting tumor growth and progression by suppressing miR-214 and activating the PTEN/PI3K/ AKT signaling pathway. A schematic description of miR-214 inhibitor delivery by GO-PEI complexes for OSCC treatment is shown in Figure 1.

\section{Experiments and Methods Preparation of GO-PEI}

GO (Aladdin, Shanghai, China) was subjected to ultrasonication for $8 \mathrm{~h}$ at $800 \mathrm{~W}$ and centrifuged at $5000 \times \mathrm{g}$ for $20 \mathrm{~min}$ to remove large GO sheets. The supernatant was filtered three times with $0.45 \mathrm{~mm}$ syringe filters, and the nano-GO collected in the filtrate was subjected to further modification. GO was linked to PEI (Sigma-Aldrich, Missouri, USA) through the formation of amide bonds using methods reported in the literature. ${ }^{28}$ Briefly, we slowly added a solution of PEI $(25-\mathrm{kDa}, 1 \mathrm{mg} / \mathrm{mL})$ to the $\mathrm{GO}$ solution (1 $\mathrm{mg} / \mathrm{mL})$. The GO-PEI complexes were obtained by mixing the PEI solution with the GO solution at a GO:PEI weight ratio of 1:3. The mixture was ultrasonicated for 15 min and stirred overnight. To remove unbound PEI, the reaction complexes were washed with $\mathrm{ddH}_{2} \mathrm{O}$ and centrifuged extensively $\left(2000 \times \mathrm{g}, 30 \mathrm{~min}, 4^{\circ} \mathrm{C}\right)$. The size distributions of GO and GO-PEI were tested using a dynamic light scattering (DLS) spectrophotometer (Otsuka Electronics, Japan). The UV-vis absorption spectrum (190-800 nm) was obtained for GO and GO-PEI samples $(10 \mu \mathrm{g} / \mathrm{mL})$ using an ultraviolet-visible spectrophotometer (Shimadzu, Japan). The surface charge of GO and GO-PEI samples was measured by a Zetasizer (Malvern Nano ZS, Malvern, UK), and the sample could be either suspended in deionized water or in cell culture medium. The internal structures of GO and GOPEI samples were observed by transmission electron microscopy (TEM, ht7700, Hitachi, Japan).

\section{Cell Viability Assay}

Human oral cancer Cal27, SCC9 and SCC25 cell lines (Geneseed, Guangzhou, China) were used in this study. The CCK-8 assay was utilized to measure the cytotoxicity of GO and the GO-PEI complexes. Briefly, the Cal27, SCC9 and SCC25 cells were cultured with GO-PEI at various concentrations for $48 \mathrm{~h}$. Then, $10 \mu \mathrm{L}$ of CCK- 8 test solution was added to each well and incubated for $2 \mathrm{~h}$ at $37^{\circ} \mathrm{C}$. The absorbance of each well was tested at $450 \mathrm{~nm}$ by a microplate reader (Molecular Devices, CA, USA). The ratio of cell viability was as follows: $(\%)=(\mathrm{OD}$ treatment group $/ \mathrm{OD}$ control group $) \times 100 \%$. This experiment was performed in triplicate.

\section{Analysis of the Cellular Uptake of GO-PEI}

The cellular uptake of GO-PEI was measured by GO-PEI labeled with FITC dye. ${ }^{29}$ GO-PEI and FITC-BSA solution (Bioss, Inc., Beijing, China) $(1 \mathrm{mg} / \mathrm{mL})$ was mixed with a mass ratio of $1: 2$ at $37^{\circ} \mathrm{C}$ for $2 \mathrm{~h}$ and then centrifuged at $10,000 \times \mathrm{g}$, and the supernatant was discarded. For the cellular uptake test, $\mathrm{Cal} 27$ and SCC 25 cells were incubated with GO-PEI-FITC $(10 \mu \mathrm{g} / \mathrm{mL})$ without serum for $24 \mathrm{~h}$. GO-PEIFITC-treated Cal27 and SCC25 cells were fixed with $4 \%$ paraformaldehyde in PBS for $15 \mathrm{~min}$ at $4{ }^{\circ} \mathrm{C}$. The cells were stained with DAPI (Sigma-Aldrich, Missouri, USA) (1:2000) for $15 \mathrm{~min}$ and observed under a laser scanning confocal microscope (Carl Zeiss, Inc, Jena Germany).

\section{miRNA Delivery Analysis}

The miR-214 inhibitor was purchased from Ribobio (Ribobio, Guangzhou, China), and the accession number was MIMAT0000661 (the sequence: ACAGCAGGCACA 


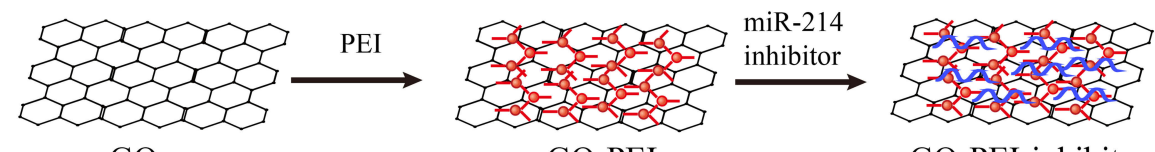

GO

GO-PEI

GO-PEI-inhibitor

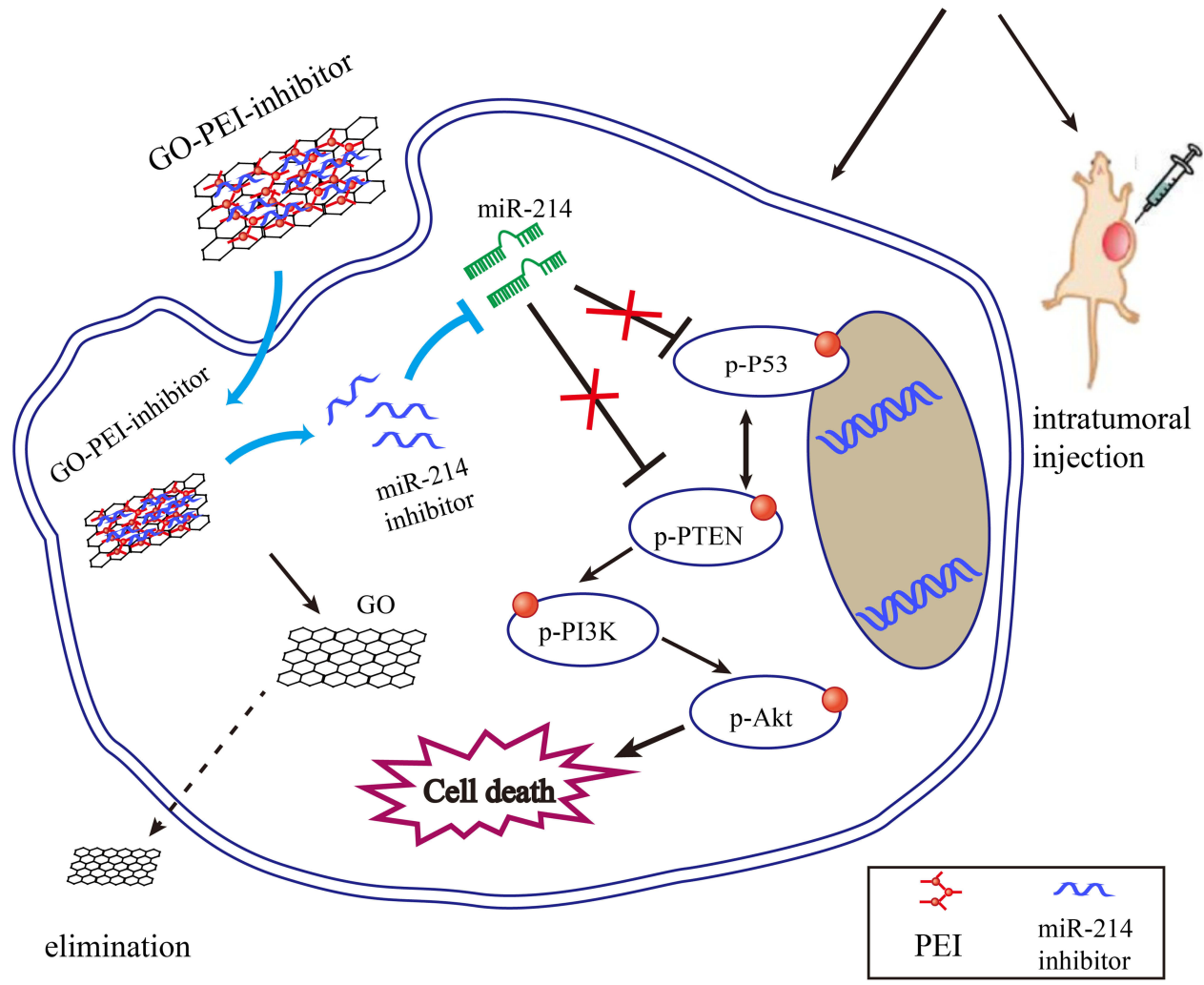

Figure I Schematic illustration shows the synthesis of GO-PEl-inhibitor complexes and miR-2I4 inhibitor delivery. GO was conjugated with PEI to form positively charged GO-PEl complexes. For miR-2। 4 inhibitor delivery, negatively charged miR-2/4 inhibitor was loaded onto the GO-PEI complexes by electrostatic interactions. The miR-2/4 inhibitor was delivered into cells and inhibited the expression and function of miR-2I4, subsequently regulating the expression of downstream genes. GO-PEI-inhibitor was applied to mice tumors through intratumoral injection.

GACAGGCAGU). GO-PEI complexes were mixed with a cy3-labeled miRNA inhibitor solution at N/P ratios of 30 for $1 \mathrm{~h}$. The mixture was incubated on ice for $1 \mathrm{~h}$, heated at $65{ }^{\circ} \mathrm{C}$ for $10 \mathrm{~min}$ and centrifuged at $10,000 \times \mathrm{g}$; then, the supernatant was removed. Cal27 and SCC9 cells were seeded in 24-well plates and cultured overnight before transfection. GO-PEI-inhibitor complexes were added to Cal27 and SSC9 cell culture medium for 1, 4, 8, 16, 24, 36, 48 and $72 \mathrm{~h}$. Cy3-miRNA delivery was analyzed using fluorescence microscopy (Olympus, Japan).

\section{Migration and Invasion Assays}

Cancer cell migration and invasion were usually evaluated using transwell assays. To measure the cell invasion ability, the upper chamber was precoated with $2 \%$ Matrigel (100 $\mu \mathrm{L}$, BD Biosciences), and $5 \times 10^{4}$ cells were seeded in the upper chamber of transwell with $200 \mu \mathrm{L}$ serum-free medium (5 $\mu \mathrm{g} / \mathrm{mL}$ lipo-inhibitor or GO-PEI-inhibitor).
Then, $600 \mu \mathrm{L}$ medium with $10 \%$ FBS was added to the lower chamber. After $24 \mathrm{~h}$ incubation, the noninvasive cells in the upper chamber were gently removed. The cells that transferred through the filter membrane were fixed and stained with a $0.1 \%$ crystal violet solution. The cell numbers on the filter were calculated in 4 random fields of view under a microscope. For the migration assay, the cells were seeded in 24-well plates and cultured to achieve $100 \%$ confluence. A $200 \mu \mathrm{L}$ pipette tip was used to make a wound through the cell monolayer. The media was aspirated, and the cells were washed twice carefully. Pictures were taken of the wounds under an inverted microscope at several time points.

\section{Immunofluorescence Staining and Western Blotting Analyses}

Cal27 cells were seeded onto coverslips in 24-well plates $\left(5 \times 10^{4}\right.$ cells/well) and cotreated with GO-PEI-inhibitor for 
24 h. After being washed with PBS, the cells were fixed, permeabilized as described, ${ }^{30}$ blocked in $3 \%$ horse serum, washed with PBS 3 times and incubated with the primary antibody (1:250 dilution) overnight at $4{ }^{\circ} \mathrm{C}$. The primary antibody was specific for p-PTEN and p-p53 (Abcam, MA, USA). After being washed with PBS, the cells were incubated with the secondary antibody (1:300, Jackson ImmunoResearch, PA, USA) for $1 \mathrm{~h}$ at room temperature in the dark. After washing, the cells were counterstained with DAPI and visualized with a fluorescence microscope. The fluorescence microscopic images were captured and analyzed using ImageJ. For the Western blot assay, cells were lysed and the protein was extracted after treatment. The protein concentration was analyzed by a BCA Protein Assay Kit (Beyotime, Shanghai, China). The same amount of protein $(30 \mu \mathrm{g})$ was loaded onto a $12 \%$ SDS-PAGE gel (Beyotime), separated by electrophoresis and then transferred onto PVDF membranes. The membranes were blocked with BSA and incubated with monoclonal antibodies against p-PTEN, PTEN (Abcam, MA, USA), p-PI3K, PI3K, p-Akt, Akt (CST, MA, USA), p-p53, or p53 (Abcam, MA, USA); the membranes were then incubated with HRP-conjugated secondary antibodies (CST). GAPDH was used as an internal control. The membranes were then reacted with an ECL Western blot substrate kit (Beyotime), and the band density was quantified using ImageJ (Protein Simple, CA, USA).

\section{qRT-PCR Analysis}

Total RNA and miRNA were isolated using RNeasy Mini and miRNeasy Mini kits (Qiagen, Valencia, CA, USA). The mRNA levels for genes were measured using SYBR Green qRT-PCR mix (Promega, Inc., USA) using the 7500 Fast RealTime PCR System (Applied Biosystems, MA, USA). The expression of miR-214 was determined using the BulgeLoop $^{\mathrm{TM}}$ miRNA qRT-PCR Kit (Ribobio, Guangzhou, China). The primers used for qRT-PCR are as follows: snail, 5'-CGGAAGCCTAACTACAGCGA-3', 3'-ACAGAGTCCC AGATGAGCATT-5'; E-cadherin, 5'-AGTCAGTTCAGACT CCAGCC-3', 3'-TGTAGCTCTCGGCGTCAAA-5'; GAPD H, 5'-GTCAAGGCTGAGAACGGGAAG-3', 3'-GAGGGG GCAGAGATGATGACC-5'.

\section{In vivo Antitumor Efficacy}

Female BALB/c nude mice were used to build the OSCC xenograft mouse model. The nude mice were provided by the Southern Medical University Animal Center at the age of 6 weeks $(20-22 \mathrm{~g})$. Animal experiments were performed with the approval of Laboratory Animal Ethics Committee at Jinan University and followed the guidelines of the National Act on the Use of Experimental Animals (China). Mice were housed five per cage on a $12 \mathrm{hr}$ light/dark cycle in a temperature and humidity-controlled room. All mice had free access to deionized water and sterilized food. SCC9 cells $\left(3 \times 10^{6}\right.$ cells in $100 \mu \mathrm{L}$ PBS) were carefully injected subcutaneously into the right flank of the mice. Once the volume of the tumor reached approximately $100 \mathrm{~mm}^{3}$ on the 10th day (defined as day 0), the mice were randomized into groups and received treatments of PBS $(30 \mu \mathrm{L}, \mathrm{n}=8)$, miR-214 inhibitor ( $5 \mathrm{mg} / \mathrm{kg}, \mathrm{n}=8)$, GO-PEI $(5 \mathrm{mg} / \mathrm{kg}$, $\mathrm{n}=8)$, or GO-PEI-inhibitor ( $5 \mathrm{mg} / \mathrm{kg}, \mathrm{n}=8)$ via intratumoral administration. The treatments were given to mice on days $0,4,8$, and 12 . The body weights and tumor sizes of the mice were monitored. The tumor volume was calculated with the following formula: tumor volume $=$ length $\times$ (width) $)^{2} / 2$. Each mouse was independently measured, and the fold-changes in tumor volume were calculated relative to the tumor volume on day 0 .

\section{Histology and Immunohistochemistry}

All mice were sacrificed on day 20, and tumors and organs were collected for H\&E staining and immunohistochemical staining. Cryostat sections were prepared, fixed in methanol and blocked with BSA for $30 \mathrm{~min}$, and then incubated with the primary antibody (1:200 dilution) overnight at $4{ }^{\circ} \mathrm{C}$. The primary antibodies were specific for PTEN, Ki67 (CST) and p53 (Abcam). The sections were washed 3 times in PBS and incubated with the secondary antibody for $2 \mathrm{~h}$ at room temperature. The samples were measured using light microscopy (Olympus, IX71, Japan).

\section{Statistical Analysis}

The data are presented as the mean $\pm \mathrm{SD}$ (standard deviation). Statistical comparisons between different groups or two groups were evaluated by one-way ANOVA test or $t$-test comparison. Statistical significance was determined with a P-value $<0.05$.

\section{Results}

\section{Characterization of GO-PEI}

\section{Nanocomplexes}

GO can load aromatic drugs efficiently via $\pi$ - $\pi$ interactions; ${ }^{31}$ however, GO carries a net negative charge, causing 
electrostatic repulsion between nucleic acids. ${ }^{32}$ Thus, to deliver the miRNA inhibitor into cells, we synthesized GOPEI at a GO:PEI weight ratio of 1:5. Synthesized GO-PEI was stable in both PBS and cell medium without obvious agglomeration. GO and GO-PEI were confirmed via TEM, and the GO-PEI complex demonstrated an overlapping surface (Figure 2A). The size distributions of GO and GO-PEI measured by DLS showed mean diameters of $136.5 \pm 35.7$ $\mathrm{nm}$ and $187.3 \pm 61.7 \mathrm{~nm}$, respectively (Figure $2 \mathrm{~B}$ ). The data suggested that the differences in the sizes between GO and GO-PEI were minor. The particle size did not change when stored at $4{ }^{\circ} \mathrm{C}$ for over 10 months (data not shown). The surface charges of GO and GO-PEI were determined using electrophoretic light scattering spectrophotometry. The zeta potentials of GO, GO-PEI and GO-PEI-inhibitor were different in water and PBS. GO in distilled deionized water $\left(\mathrm{ddH}_{2} \mathrm{O}\right)$ and $\mathrm{PBS}$ possessed a negative charge. GO-PEI and GO-PEI-inhibitor were positively charged in both $\mathrm{ddH}_{2}$ $\mathrm{O}$ and PBS; however, the positive charges of GO-PEIinhibitor were lower than those of GO-PEI. It was suggested that the GO-PEI complex could bind to negatively charged
miRNA inhibitors and be used to deliver miRNA inhibitors into cells (Figure 2C). The UV-vis spectrum showed an absorption peak at $280 \mathrm{~nm}$ for miRNA inhibitor and GOPEI-inhibitor, which meant that the miRNA inhibitor loaded on GO-PEI (Figure 2D).

\section{Cell Uptake of GO-PEI Analysis}

The biocompatibility of GO-PEI attaches great importance to drug carrier applications. We investigated the cytotoxicity of GO-PEI in Cal27, SCC9 and scc25 cells using the CCK-8 kit. The GO-PEI complexes did not show apparent cytotoxicity even at a dose of $40 \mu \mathrm{g} / \mathrm{mL}$. More than $80 \%$ of cells exposed to GO-PEI $(20 \mu \mathrm{g} / \mathrm{mL})$ remained viable (Figure 3A). The GO-PEI complexes showed less toxicity than linear PEI alone in cells as previously reported. ${ }^{33}$ In line with these results, we chose a dose of $10 \mu \mathrm{g} / \mathrm{mL}$ for GO-PEI in the following experiments to investigate its delivery efficiency in cells. To shed light on the uptake of GO-PEI by cells, TEM images were used to confirm the intracellular delivery of the GO-PEI complexes. As shown in Figure 3B, GO-PEI complexes were located mainly in
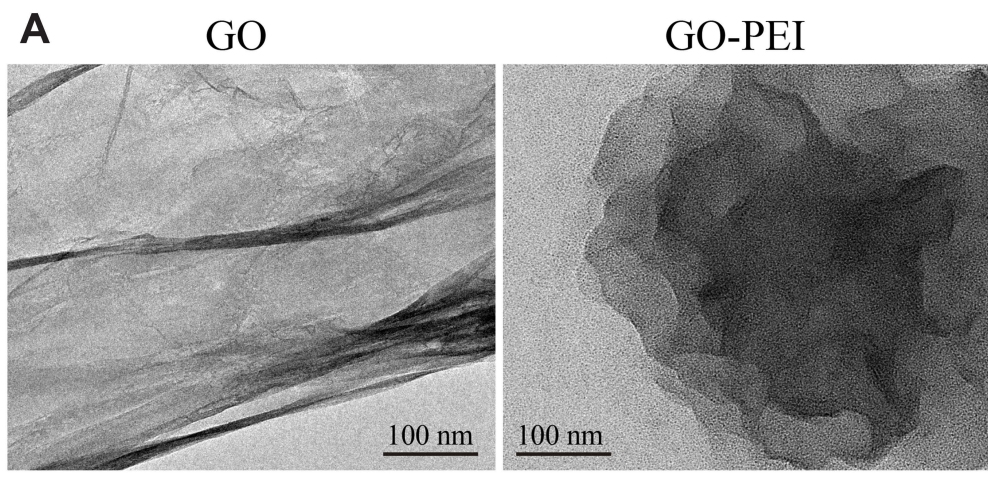

C

\begin{tabular}{|c|c|c|}
\hline & In ddH $_{2} \mathrm{O}(\mathrm{mV})$ & In PBS $(\mathrm{mV})$ \\
\hline GO & $-33.40 \pm 3.53$ & $-14.06 \pm 2.41$ \\
\hline GO-PEI & $27.83 \pm 3.23$ & $34.5 \pm 4.25$ \\
\hline GO-PEI-inhibitor & $21.6 \pm 1.25$ & $28.5 \pm 2.12$ \\
\hline
\end{tabular}

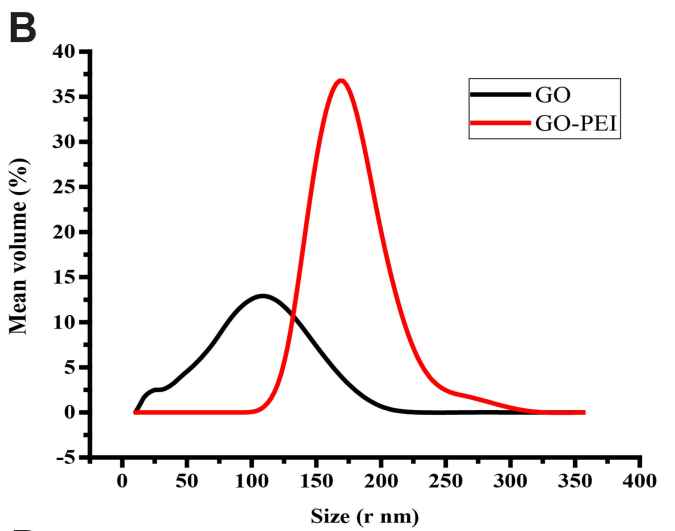

D

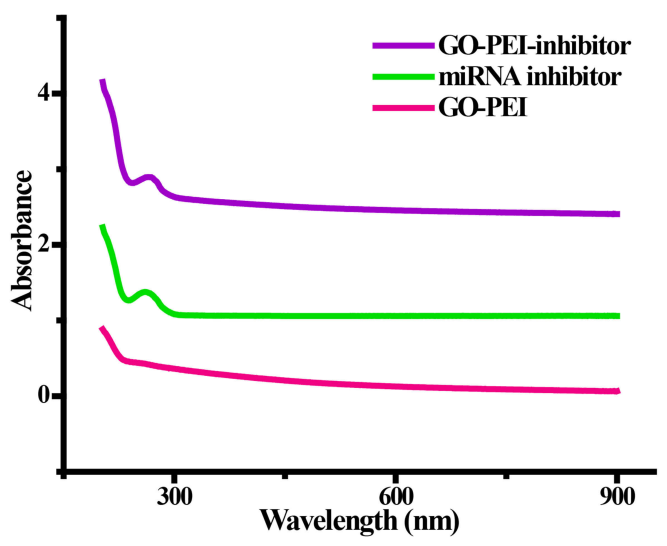

Figure 2 Characterization of GO-PEI complexes. (A) SEM images of GO and GO-PEl complexes. Scale bars: $100 \mathrm{~nm}$. (B) Measurement of the size distribution of GO and GO-PEI by DLS. (C) Measurement of the zeta potential of GO and the GO-PEl complexes in water and PBS solution. (D) UV-vis spectra normalized by their extinction coefficients at $260 \mathrm{~nm}$. The purple line is for the GO-PEI-miR-2I4 inhibitor complex, the green line is for free miR-2I4 inhibitor sense strand, and the red line for GO-PEI. 
A

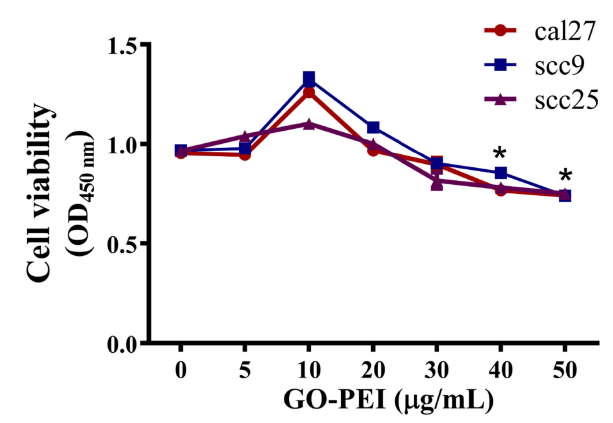

B

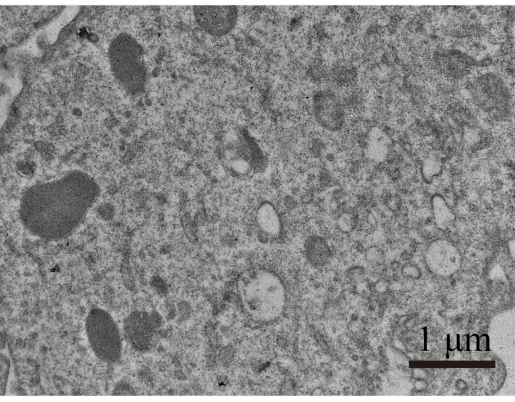

GO-PEI

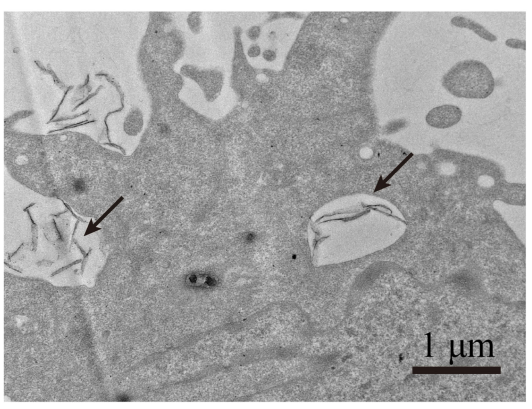

C

\section{control}

GO-PEI-FITC

Local magnification
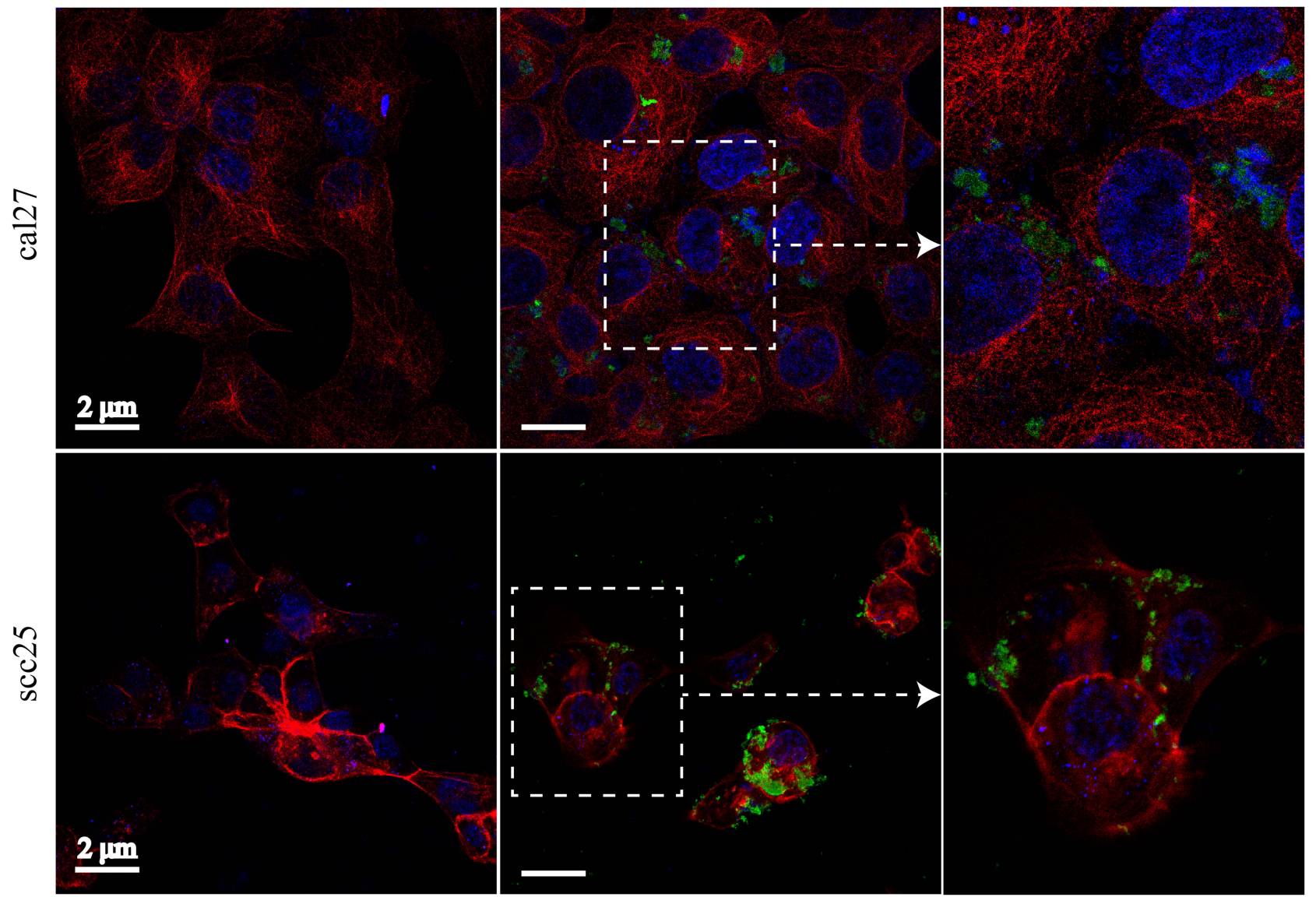

Figure 3 Cell uptake of GO-PEI. (A) Relative cell viabilities of Cal27, SCC9 and scc25 cells treated with different concentrations of GO-PEI for 24 h. (B) TEM images of nontreated cells (named control) and GO-PEl-treated cells $(5 \mu \mathrm{g} / \mathrm{mL}$ ). Scale bars: I $\mu \mathrm{m}$. (C) Fluorescent images of FITC-labeled GO-PEI (green) within Cal27 and scc25 cells are shown. The cell cytoskeleton was stained with $\alpha$-tubulin (red), and the nuclei were stained with DAPI (blue). The right panel shows enlarged images of white squares in the image of cells incubated with GO-PEI. Scale bars: $2 \mu \mathrm{m}$.

the cell cytoplasm, and only a few were located within the nucleus of SCC9 cells. Furthermore, cellular uptake studies were also conducted in $\mathrm{Ca} 27$ and scc 25 cells. Cells were incubated with the FITC-labeled GO-PEI complexes and then visualized by laser scanning confocal microscopy (CLSM). The cellular nuclei of cells were stained with
DAPI, and the membranes were stained with $\alpha$-tubulin. GO-PEI particles were located mainly in the cell cytoplasm and some adhered to the plasma membrane following $8 \mathrm{~h}$ incubation, and an increased number of GOPEI complexes were visualized in cells over time (Figure 3C). 


\section{Efficient Delivery of the miRNA Inhibitor by GO-PEl into Cells}

To show that GO-PEI was suitable for miRNA inhibitor loading, a miRNA inhibitor was labeled with cy3 to track the GO-PEI-based gene delivery and assess the transfection efficiency. Cal27 and SCC9 cells were incubated with different nitrogen/phosphate $(\mathrm{N} / \mathrm{P})$ ratios of GO-PEImiRNA inhibitor, and the highest fluorescence was detected at an N/P ratio of 30 . Fluorescence was not observed when GO-PEI was used alone or when the miRNA inhibitor was used alone (Figure 4A). Moreover, the GO-PEI-inhibitor complexes (the N/P ratio was 30) showed a slow release in cells where the fluorescence was strongest at $24 \mathrm{~h}$ postincubation. As time increased, the fluorescence weakened but was maintained for more than
$72 \mathrm{~h}$ (Figure 4B). For all of the above, the miRNA inhibitors were completely loaded within GO-PEI complexes with N/P ratios greater than 30 . The cy3-labeled inhibitor was mixed with GO-PEI or lipofectamine for $30 \mathrm{~min}$, and then the respective complexes were delivered into $\mathrm{Cal} 27$ and SCC9 cells. GO-PEI-inhibitor revealed significantly higher transfection efficiencies (approximately 50\%) compared to lipofectamine (approximately 30\%) and naked inhibitor (5\%) (Figure 4C). These results suggested that the miR-214 inhibitor alone could not penetrate the cell membrane since the negative charge and rapid degradation in the culture medium. The fluorescence of cells treated with lipo-inhibitor was weaker than that of cells treated with GO-PEI-inhibitor complexes, suggesting that GO-PEI complexes had the advantage in gene delivery.
A

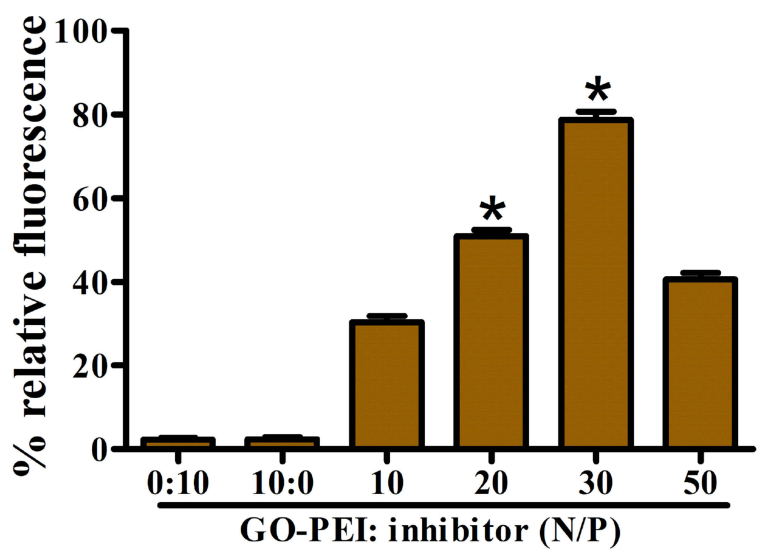

C

control

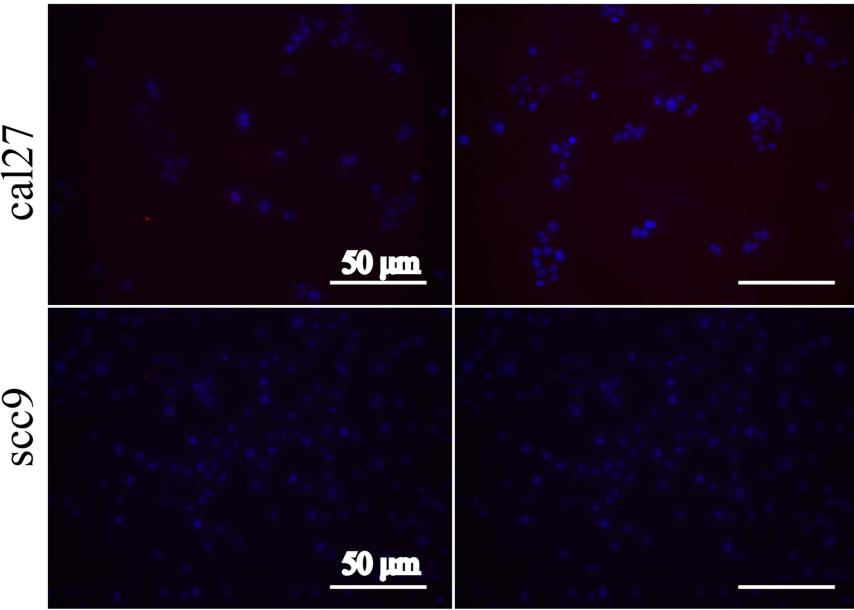

B

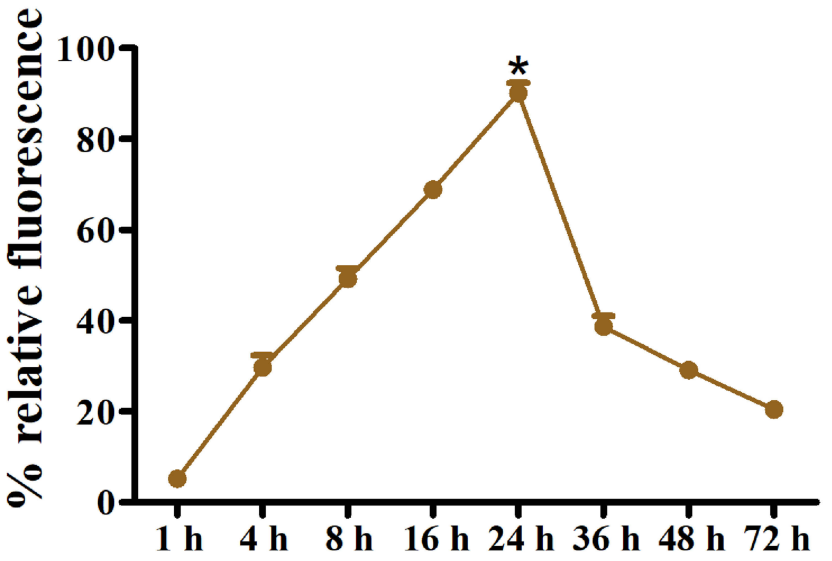

Figure 4 Efficient delivery of miRNA inhibitor by GO-PEI into cells. (A) The relative fluorescence of GO-PEI and the miR-2I4 inhibitor at various N/P ratios (0, I0, 20, 30 and 50). *P < 0.05. (B) The relative fluorescence of GO-PEl and miR-2I4 inhibitor at N/P ratios of 30 at different time points (I, 4, 8, I6, 24, 36, 48 and 72 h). *P < 0.05. (C) Fluorescent images of cy3-labeled miR-2I 4 (red) delivered by GO-PEI within Cal27 and SCC 9 cells are shown. The nuclei were stained with DAPI (blue). Scale bars: 50 um. 


\section{GO-PEl-Inhibitor Inhibits Cell Migration and Metastasis in Cal27 Cells}

Given the critical roles of miR-214 in OSCC, ${ }^{13,14,34}$ we investigated the biological function of the miR-214 inhibitor in Cal27 cells delivered via GO-PEI complexes. Transwell assays and wound healing assays were performed to investigate the effect of GO-PEI-inhibitor cell metastasis and migration. Cal27 cells were incubated with a naked inhibitor $(50 \mathrm{nM})$, lipo-inhibitor $(50 \mathrm{nM})$ or GO-PEIinhibitor (the concentration of the inhibitor was $50 \mathrm{nM}$ ). As shown in Figure 5A and B, Cal27 cells incubated with GO-PEI-inhibitor had a markedly reduced number of invading cells $(197.8 \pm 26.89)$ compared with the number of invading cells from cells incubated with either the naked inhibitor (518.3 \pm 16.65$)$ or the lipo-inhibitor (505.9 \pm 19.57) for $48 \mathrm{~h}$. In wound healing assays, the cells were allowed to migrate in a cell-free gap created by pipette tips in the culture plate. Cells incubated with GO-PEI-inhibitor were less present in the gap, and cell migration was inhibited; in addition, the ratios of the initial wound area from cells treated with GO-PEI-inhibitor were much larger than the ratios from cells treated with the naked inhibitor or lipoinhibitor (Figure 5C and D). In addition, the qRT-PCR results showed that compared to the control cells and cells treated with lipo-inhibitor, cells treated with GO-PEIinhibitor had a decreased expression of snail and an increased expression of E-cadherin (Figure 5E). Snail is proven to be a master gene for epithelial-mesenchymal transition (EMT). ${ }^{35,36}$ These results suggest that the transfection level of GO-PEI-inhibitor was sufficient to inhibit the role of miR-214 in regulating osteosarcoma cellular motility, metastasis and migration.
A control

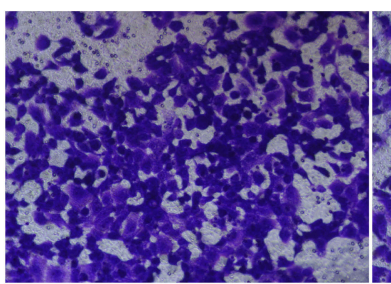

lipo-inhibitor
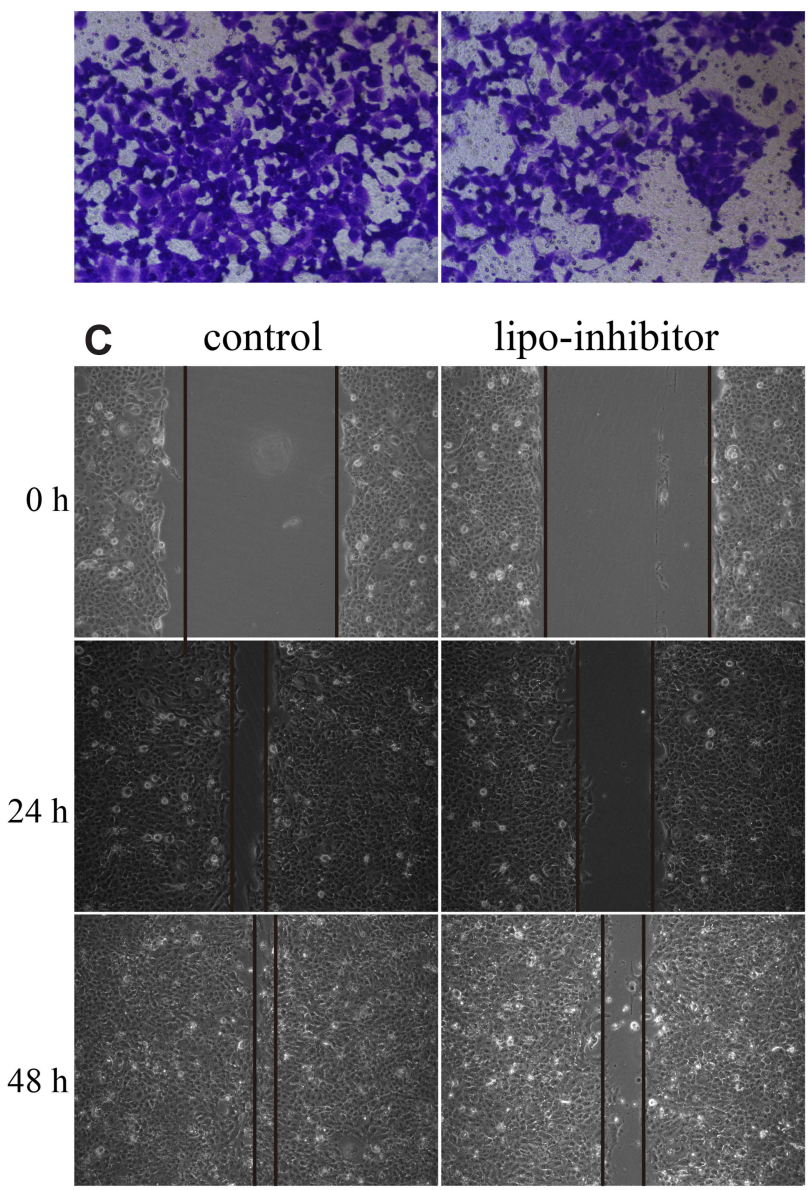

lipo-inhibitor
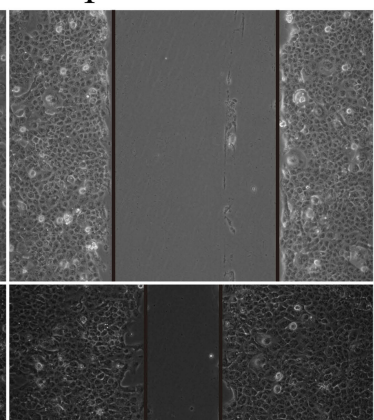

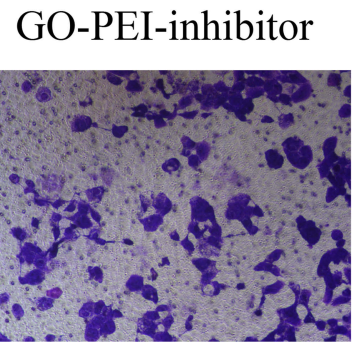

GO-PEI-inhibitor

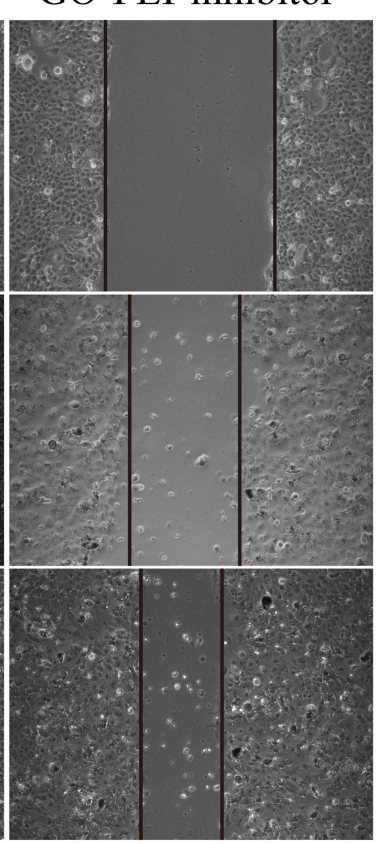

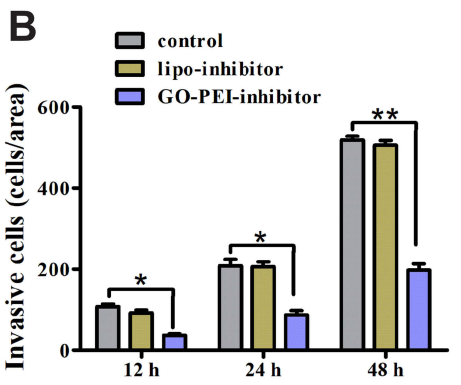

D
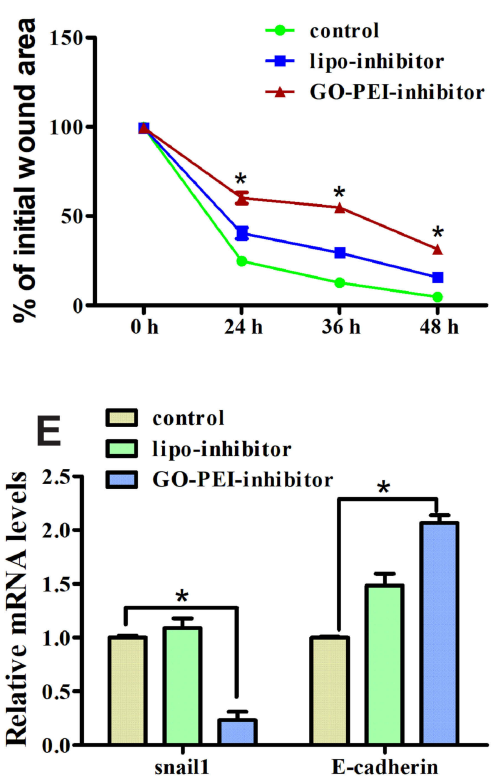

Figure 5 GO-PEl-inhibitor inhibits cell migration and metastasis in Cal27 cells. (A) Cal27 cell invasion was measured using Matrigel-coated chamber filters for 24 h. (B) Statistical analysis of the invading cell ratio is presented for each group. ${ }^{*} \mathrm{P}<0.05$. ${ }^{*} * \mathrm{P}<0.0 \mathrm{I}$. (C) The wounds of confluent Cal27 cells were created using I00 $\mu \mathrm{L}$ yellow tips and were incubated with lipo-inhibitor or GO-PEl-inhibitor $(5 \mu \mathrm{g} / \mathrm{mL})$. Images of the wounds at 0,24 and $48 \mathrm{~h}$ are shown, and a cell-free gap is bordered by the pair of black lines. (D) Statistical analysis of cell migration was performed by calculating the ratio of the final cell-free gap to the initial wound area. *P<0.05. (E) The expression levels of snaill and E-cadherin after treatment with lipo-inhibitor or GO-PEl-inhibitor were evaluated by qRT-PCR. $*$ P $<0.05$. 


\section{Efficient Cell Signaling in OSCC Cells Induced by GO-PEI-Inhibitor Complexes}

In malignancy, miR-214 targets PTEN or p53, resulting in the inhibition of cell apoptosis. ${ }^{37-40}$ To obtain further insight into the mechanisms of GO-PEI-inhibitor in OSCC cell proliferation and progression, we examined the effect of GO-PEI-inhibitor on PTEN and p53-related signaling pathways. Cal27 cells were treated with GO-PEI -inhibitor $(50 \mathrm{nM})$, lipo-inhibitor $(50 \mathrm{nM})$ or PBS for 24 $\mathrm{h}$. Immunostaining of PTEN and p53 was visualized in GO-PEI-inhibitor-treated cells and contrasted with cells treated with PBS or lipo-inhibitor. PTEN protein immunostaining was mainly found on the cell membrane and in the cytoplasm of Cal27 cells, whereas p53 was localized in mitochondrial and nuclear membranes. The expression levels of PTEN and p53 were significantly increased in cells treated with GO-PEI-inhibitor compared to those in cells treated with PBS and lipo-inhibitor (Figure 6A). PTEN and p53 are tumor suppressors in most human cancers ${ }^{41}$ and PTEN interacts with p53 in a complex network; ${ }^{42}$ PTEN has been shown to regulate p53 stability, ${ }^{43}$ while p53 can enhance PTEN transcription. ${ }^{44}$ Western blot analysis identified the activation of PTEN and p53 with GO-PEI-inhibitor treatment. Compared to the control and lipo-inhibitor treatments, treatment with GO-PEI-inhibitor significantly enhanced the protein levels of phospho-PTEN and phospho-p53 (Figure 6B). Numerous studies have demonstrated that PTEN is the central negative regulator of PI3K/AKT-mediated signaling, preventing tumor development and progression. ${ }^{45} \mathrm{P} 53$ also creates a critical connection to downstream effectors of growth inhibition or cell death. PTEN/PI3K/Akt promotes p53 translation and protein stability. ${ }^{42}$ To further confirm the signaling pathways induced by GO-PEIinhibitor in cells, the protein levels of phospho-PI3K and phospho-Akt were also assessed. We found that GO-PEIinhibitor significantly decreased the expression of p-PI3K and p-Akt, whereas the total levels of PI3K and Akt remained unchanged (Figure $6 \mathrm{~B}$ and $\mathrm{C}$ ).

Coincident with the above results, we found that the level of miR-214 in cells treated with GO-PEI-inhibitor was remarkably reduced compared to the level in cells treated with PBS and lipo-inhibitor (Figure 6D). These results suggest that GO-PEI-inhibitor successfully suppressed the expression level of miR-214; this suppression consequently affected the targeted molecules of PTEN and p53 and blocked the signaling pathway of PI3K/Akt.
GO-PEI-Inhibitor Displayed High Anticancer Efficiency in the OSCC Xenograft Mouse Model by Intratumoral Injection

To examine the therapeutic efficacy of GO-PEI-inhibitor, an OSCC xenograft mouse model was generated by subcutaneous transplantation of SCC9 cells into immunodeficient mice as previously reported. ${ }^{46}$ Once the volume of tumor reached approximately $100 \mathrm{~mm}^{3}$, the mice were randomized into 4 groups and received intratumoral injection of either GO-PEI-inhibitor ( $3 \mathrm{mg} / \mathrm{kg}$ ), GO-PEI ( $3 \mathrm{mg} /$ $\mathrm{kg})$, the inhibitor $(30 \mu \mathrm{g})$ or $10 \%$ PBS 4 times. The body weight and tumor size of the mice were monitored every 3 days. Representative tumor images after different treatments for 20 days are shown in Figure 7A. The volume of the tumors during treatment is shown in Figure 7B. On day 21, tumors from mice treated with PBS, GO-PEI and naked inhibitor had grown significantly; however, the average tumor volumes of the mice in the GO-PEIinhibitor-treated groups were approximately $46.2 \%$ smaller than those of the mice in the PBS-treated groups. The tumor sizes had no obvious difference between the PBSor naked inhibitor-treated groups, which suggests that the inhibitor alone has no therapeutic effect on OSCC xenograft tumors. The rapid degradation of the naked inhibitor in vivo limits its role as a tumor therapeutic. ${ }^{47}$ During the entire experiment, the body weight of these groups showed no significant differences (Figure 7C), and the animal behavioral abnormalities were not observed in either the control or treated groups. We deduced that in contrast to the naked inhibitor, the GO-PEI complex's slow release of the miR-214 inhibitor enhanced the anticancer efficacy and long-term effects. Therefore, GO-PEI can serve as a drug delivery vehicle that can enhance the efficacy of the loaded agent.

Pathological examinations were performed at the end of the experiment. H\&E staining of xenograft tumors showed that the tumors in PBS- and naked inhibitor-treated mice were composed of masses of malignant cells; however, those of GO-PEI- or GO-PEI-inhibitor-treated mice contained necrotic cell masses with nuclear chromatin condensation and fragmentation, as well as cell shrinkage. Moreover, compared with PBS- and naked inhibitor-treated tumors, a large number of lymphocytes infiltrated the surrounding GO-PEI-inhibitor aggregation, and the infiltrated lymphocytes might have a positive relationship with tumor shrinkage (Figure 7D). Furthermore, IHC staining showed that the positive expression of p-PTEN and p-p53 was significantly 


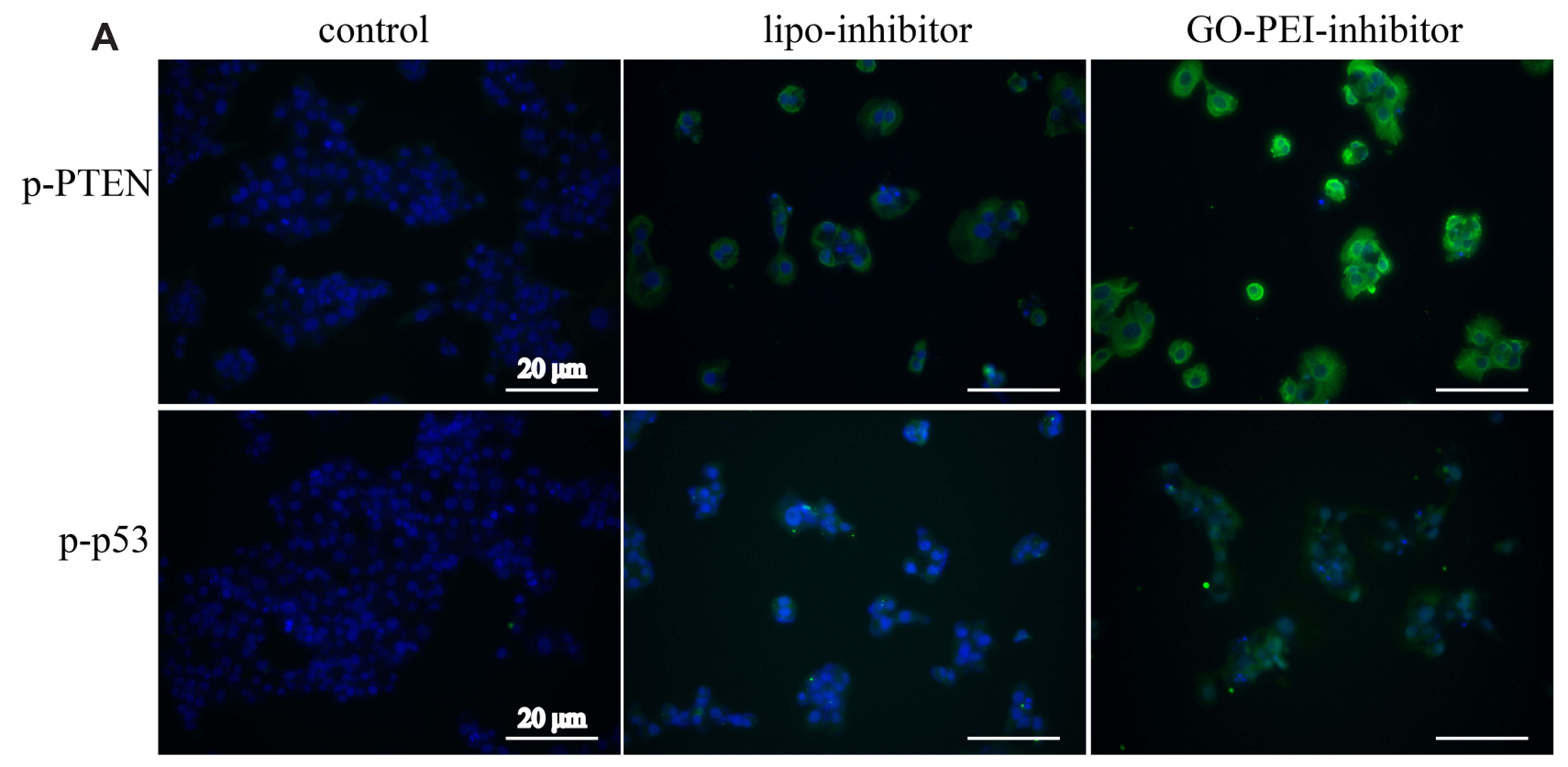

B control lipo-inhibitor GO-PEI-inhibitor
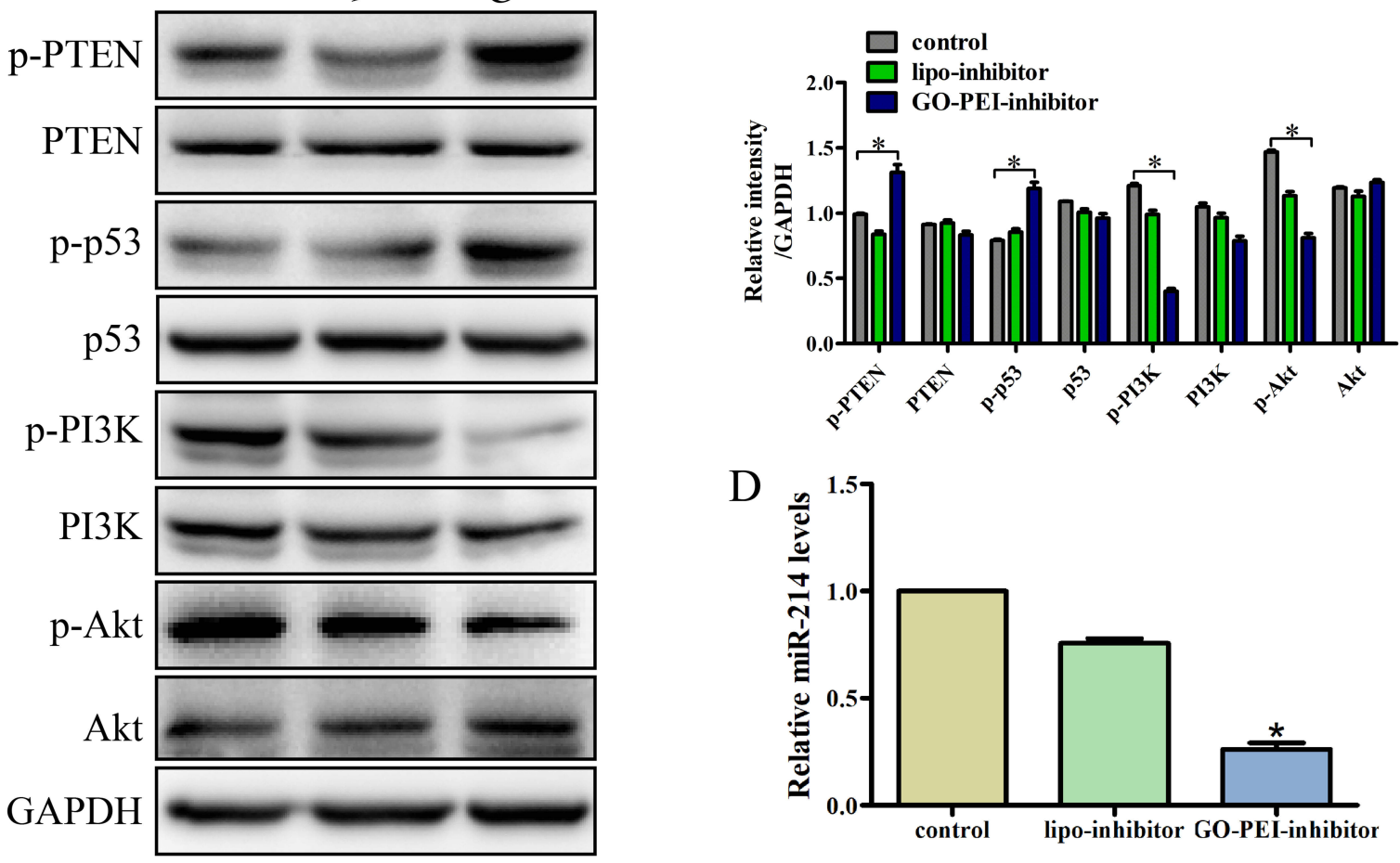

$\mathrm{D}$

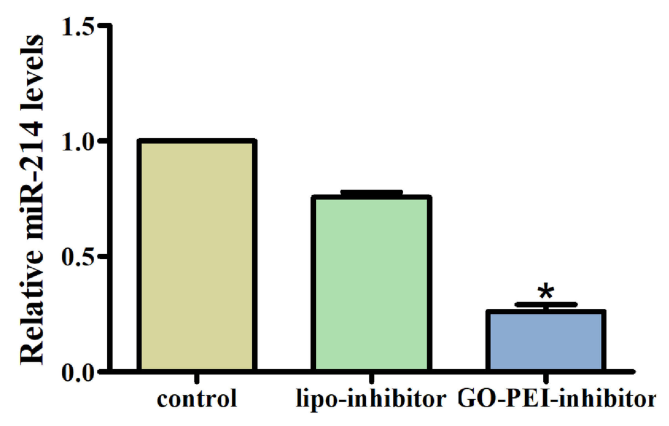

Figure 6 Efficient cell signaling in OSCC cells induced by GO-PEl-inhibitor complexes. (A) Representative immunofluorescence images of p-PTEN and P-p53 after incubation with lipo-inhibitor or GO-PEl-inhibitor. Scale bars: $20 \mu \mathrm{m}$. (B and C) The expression levels of p-PTEN, PTEN, P-p53, p53, p-PI3K, PI3K, p-Akt and Akt after incubation with lipo-inhibitor or GO-PEl-inhibitor were evaluated by Western blotting. ${ }^{*} \mathrm{P}<0.05$. (D) miR-2। 4 expression in cells after treatment with lipo-inhibitor or GOPEl-inhibitor was measured. $* \mathrm{P}<0.05$.

higher in GO-PEI-inhibitor-transfected OSCC tissues than in PBS- and naked inhibitor-treated tissues (Figure 7E). These in vivo results were consistent with the in vitro data, suggesting that miR-214 delivered by GO-PEI could suppress OSCC tumorigenesis via the regulation of the PTEN and $\mathrm{p} 53$ proteins. In addition, the H\&E staining of the organs (lungs, liver, spleen and kidneys) showed that there were no visible differences observed in organs in all the treated groups, 

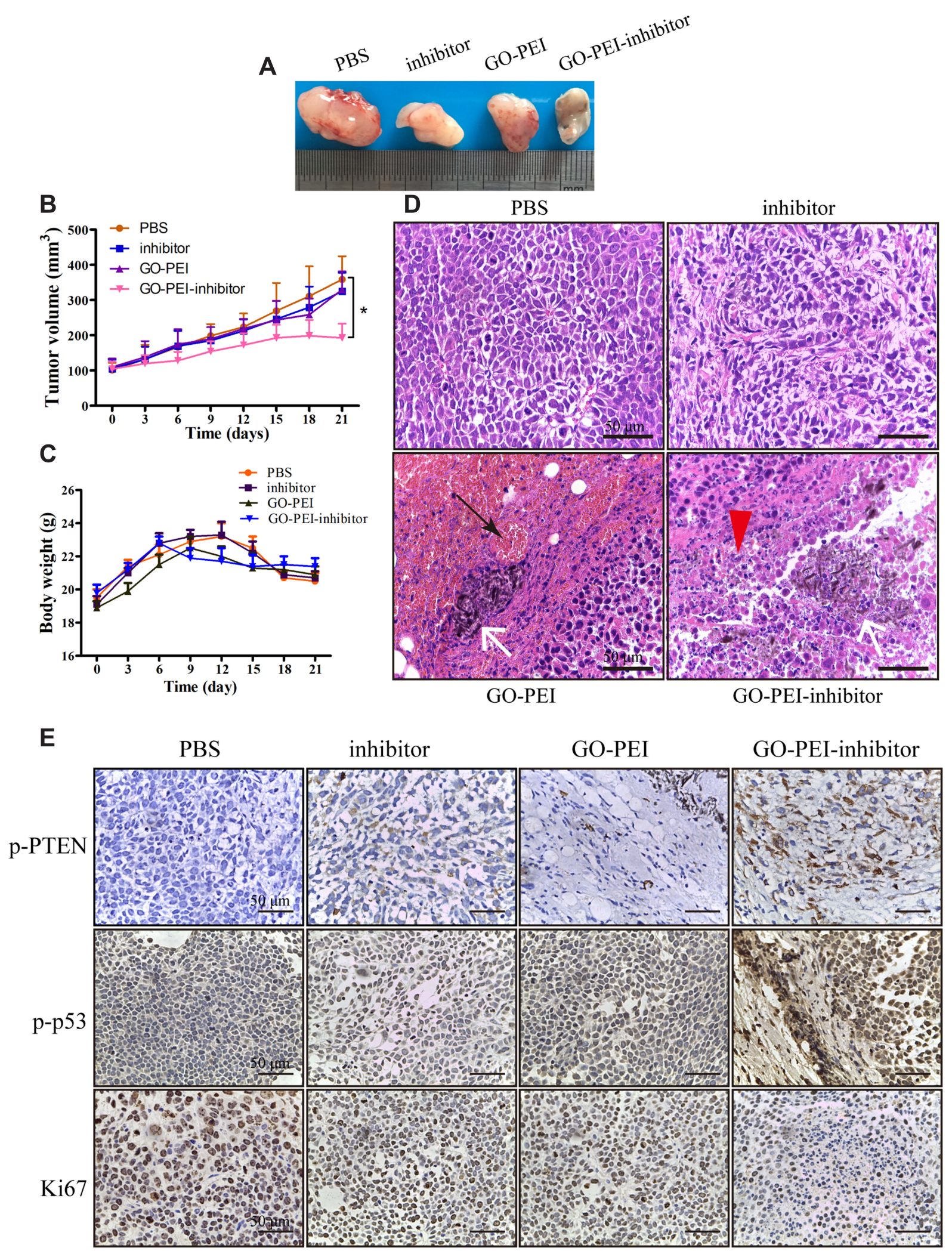

Figure 7 GO-PEl-inhibitor displayed high anticancer efficiency in the OSCC xenograft mouse model by intratumoral injection. (A) Representative images of tumor tissue treated with PBS, the miR-2I4 inhibitor, GO-PEI or GO-PEI-inhibitor complexes $(30 \mu \mathrm{L})$. (B) Relative changes in tumor volume at different time points. The values are presented, $n=5$. ${ }^{*}<<0.05$. (C) Relative changes in body weight over time and the values are presented, $n=5$. (D) Representative images of H\&E staining of tumor tissues, the black arrow points to the blood vessel, the white arrow points to the accumulated GO-PEl and the red arrow points to the dead cells. Scale bars: $50 \mu \mathrm{m}$. (E) Immunohistochemical staining of p-PTEN, p-p53 and Ki67 in different treatment groups is shown. Scale bars: $50 \mu \mathrm{m}$. 
which means that GO-PEI-inhibitor complexes were nontoxic to organs (Figure 8).

\section{Discussion}

Gene therapy, such as siRNA, miRNA and miRNA inhibitors, has been shown to exhibit low toxicity and high gene knockdown efficiency in the treatment of cancers. ${ }^{48}$ Previous reports suggested synergetic miRNA as an effective treatment of cancers without toxicity to normal cells. ${ }^{11,49,50}$ However, the instability of nucleic acid in vivo impedes further applications of gene therapy. ${ }^{47}$ In the last decade, many efforts have been directed toward the development of nanomaterials, and GO has been extensively used in drug delivery. ${ }^{51,52}$ The large surface area of GO is an incomparable advantage for drug or gene delivery. ${ }^{24,53}$ Moreover, there were no specific antiOSCC nucleic acids that utilized GO as a gene delivery nanocarrier utilized in vitro and in vivo. ${ }^{54,55}$ In reality, the size of GO affected its function in gene delivery. If the size of GO is too large, it will easily be deposited in the blood stream; if GO is too small, it will be easily phagocytized and cleared. Thus, we made the size of GO-PEI complexes in the range of $150-400 \mathrm{~nm}$ to ensure miR-214 inhibitor loading and to avoid phagocytosis by phagocytic cells.

Many efforts have been undertaken that testify to the fact that miR-214 is a novel biomarker and potential therapeutic target for various diseases in vitro and in vivo. ${ }^{12,34,56}$ It has been shown that miR-214 is upregulated in OSCCs and contributes to cisplatin chemoresistance. ${ }^{12,15}$ This study is the first report using functionalized GO with PEI to deliver a miR-214 inhibitor for OSCC therapy in vitro and in vivo. The GO-PEI complexes can effectively deliver nucleic acids due to their "proton sponge effect" ${ }^{54,57,58}$ However, the high molecular weight of PEI has been related to high cytotoxicity. ${ }^{59,60}$ Thus, GO has mainly been employed to mitigate these adverse effects of PEI. ${ }^{61,62}$ GO-PEI complexes showed a lower cytotoxicity and higher transfection efficiency than lipofectamine and effectively protected miRNA inhibitors from DNase/ RNase-mediated degradation.

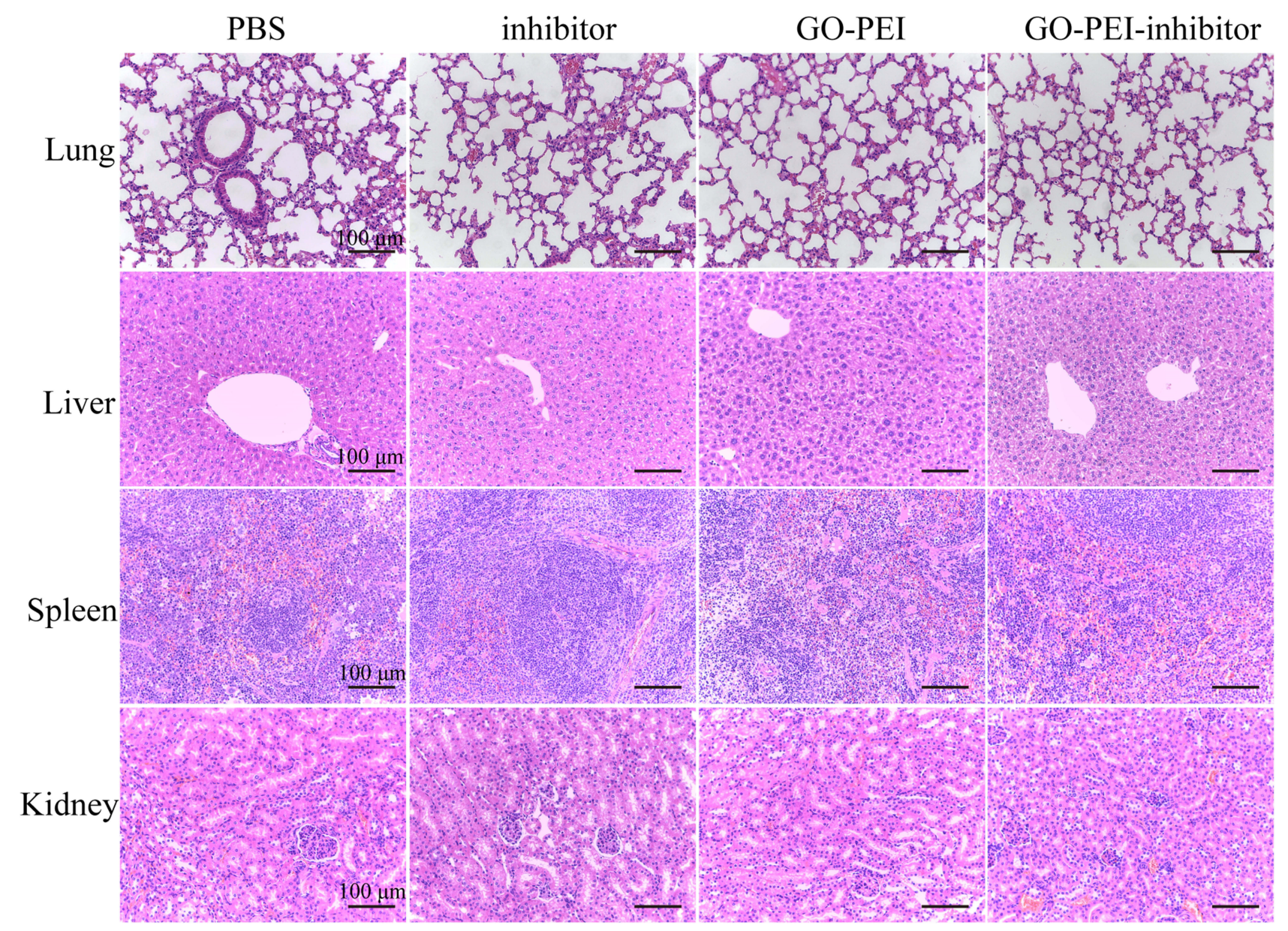

Figure 8 Histological analysis of organs after GO-PEI-inhibitor treatment. H\&E staining assay of lung, liver, spleen and kidney tissues after an intratumoral injection of saline, the miR-2I4 inhibitor, GO-PEI or GO-PEI-inhibitor complexes $(30 \mu \mathrm{L})$ for 20 days. Experiments were repeated 3 times. Scale bar: $100 \mu \mathrm{m}$. 
According to the transwell and wound healing results, the GO-PEI-inhibitor complexes play essential roles in regulating OSCC cell migration and invasion, leading to the decreased expression of snail and the increased expression of E-cadherin in cells. These results are consistent with previous reports. ${ }^{63-65}$ Furthermore, we found that the inhibition of miR-214 in cells by GO-PEI-inhibitor induced the upregulation of the PTEN and p53 proteins, consequently inhibiting the activation of the PI $3 \mathrm{~K}$ and Akt proteins. Accumulating evidence suggests that the p53 protein cooperates with PTEN and mediates the downstream signaling pathways, which might be an essential blockage in tumors. ${ }^{42,66-68}$ miR-214 induces tumor cell survival and proliferation and drug resistance by targeting the 3'-untranslated region (UTR) of PTEN, activating the Akt pathway. ${ }^{40,69,70}$ miR-214 also targets p53, leading to an increased cell population and cancer cell invasion ability. $^{34,37,38}$ However, GO-PEI-inhibitor effectively inhibited the level of miR-214 and prevented tumor cell migration and invasion.

Our in vivo antitumor study showed that the tumor volume growth was reduced up to $46 \%$ by the synergistic GO-PEI-inhibitor complexes. The body weight of the tumor-bearing mice was not influenced by GO-PEIinhibitor. In agreement with the in vitro results, GO-PEIinhibitor considerably induced PTEN and p53 protein expression in OSCC xenograft tumors. Moreover, intratumoral injection had no side effects on internal organ tissues or associated mortality.

\section{Conclusions}

In this work, the extent of suppression of invasion and migration due to the GO-PEI-inhibitor was comparable to that of the lipofectamine-inhibitor complexes. GO-PEI could serve as an effective nucleic acid carrier. This technology could deliver other therapeutic nucleic acids or nucleic acid inhibitors for the treatment of other tumors or diseases. In summary, this study revealed a novel and promising application of GO-PEI complexes for delivering synthetic nucleic acids in cancer therapy.

\section{Acknowledgment}

This work was supported by the National Natural Science Foundation of China (No. 81703120, Beijing, China), the Natural Science Foundation of Guangdong Province (2017 A030310365, Guangzhou, China), and the Guangdong Provincial Medical Research Foundation (A2016360, Guangzhou, China).

\section{Disclosure}

The authors declare no conflicts of interest in this work.

\section{References}

1. Radhika T, Jeddy N, Nithya S, Muthumeenakshi RM. Salivary biomarkers in oral squamous cell carcinoma - an insight. J Oral Biol Craniofac Res. 2016;6(Suppl 1):S51-s54. doi:10.1016/j.jobcr.2016. 07.003

2. Salahshourifar I, Vincent-Chong VK, Kallarakkal TG, Zain RB. Genomic DNA copy number alterations from precursor oral lesions to oral squamous cell carcinoma. Oral Oncol. 2014;50(5):404-412. doi:10.1016/j.oraloncology.2014.02.005

3. Lee CE, Vincent-Chong VK, Ramanathan A, et al. Collagen Triple Helix Repeat Containing-1 (CTHRC1) Expression in Oral Squamous Cell Carcinoma (OSCC): prognostic value and clinico-pathological implications. Int J Med Sci. 2015;12(12):937-945. doi:10.7150/ ijms. 11605

4. Marsh D, Suchak K, Moutasim KA, et al. Stromal features are predictive of disease mortality in oral cancer patients. J Pathol. 2011;223(4):470-481. doi:10.1002/path.2830

5. Conde J, Oliva N, Atilano M, Song HS, Artzi N. Self-assembled RNA-triple-helix hydrogel scaffold for microRNA modulation in the tumour microenvironment. Nat Mater. 2016;15(3):353-363. doi:10. 1038/nmat4497

6. Ma W, Sun M, Fu P, et al. A chiral-nanoassemblies-enabled strategy for simultaneously profiling surface glycoprotein and microRNA in living cells. Sci J Public Health. 2017;29(42):431-9.

7. Cao P, Zhou L, Zhang J, et al. Comprehensive expression profiling of microRNAs in laryngeal squamous cell carcinoma. Head Neck. 2013;35(5):720-728. doi:10.1002/hed.v35.5

8. Joshi GK, Deitz-McElyea S, Johnson M, Mali S, Korc M, Sardar R. Highly specific plasmonic biosensors for ultrasensitive microRNA detection in plasma from pancreatic cancer patients. Nano Lett. 2014;14(12):6955-6963. doi:10.1021/n1503220s

9. Tran N, O’Brien CJ, Clark J, Rose B. Potential role of micro-RNAs in head and neck tumorigenesis. Head Neck. 2010;32(8):1099-1111. doi:10.1002/hed.21356

10. Kasinski AL, Slack FJ. Epigenetics and genetics. MicroRNAs en route to the clinic: progress in validating and targeting microRNAs for cancer therapy. Nat Rev Cancer. 2011;11(12):849-864. doi:10. $1038 /$ nrc3166

11. Chen Y, Gao DY, Huang L. In vivo delivery of miRNAs for cancer therapy: challenges and strategies. Adv Drug Deliv Rev. 2015;81:128-141. doi:10.1016/j.addr.2014.05.009

12. Scapoli L, Palmieri A, Lo Muzio L, et al. MicroRNA expression profiling of oral carcinoma identifies new markers of tumor progression. Int J Immunopathol Pharmacol. 2010;23(4):1229-1234. doi:10.1177/ 039463201002300427

13. Gong Y, Yang H, Tian X. Elucidating the mechanism of miRNA-214 in the regulation of gingival carcinoma. Exp Ther Med. 2017;13 (5):2544-2550. doi:10.3892/etm.2017.4264

14. Yoon AJ, Wang S, Shen J, et al. Prognostic value of miR-375 and miR-214-3p in early stage oral squamous cell carcinoma. Am J Transl Res. 2014;6(5):580-592.

15. Yu ZW, Zhong LP, Ji T, Zhang P, Chen WT, Zhang CP. MicroRNAs contribute to the chemoresistance of cisplatin in tongue squamous cell carcinoma lines. Oral Oncol. 2010;46(4):317-322. doi:10.1016/j. oraloncology.2010.02.002

16. Stenvang J, Petri A, Lindow M, Obad S, Kauppinen S. Inhibition of microRNA function by antimiR oligonucleotides. Silence. 2012;3 (1):1. doi:10.1186/1758-907X-3-1

17. Hydbring P, Badalian-Very G. Clinical applications of microRNAs. F1000Res. 2013;2:136. doi:10.12688/f1000research 
18. Krutzfeldt J, Rajewsky N, Braich R, et al. Silencing of microRNAs in vivo with 'antagomirs'. Nature. 2005;438(7068):685-689. doi:10.10 38/nature04303

19. Peng B, Chen Y, Leong KW. MicroRNA delivery for regenerative medicine. Adv Drug Deliv Rev. 2015;88:108-122. doi:10.1016/j. addr.2015.05.014

20. Stiegelbauer V, Perakis S, Deutsch A, Ling H, Gerger A, Pichler M. MicroRNAs as novel predictive biomarkers and therapeutic targets in colorectal cancer. World J Gastroenterol. 2014;20(33):11727-11735. doi:10.3748/wjg.v20.i33.11727

21. Chen Y, Tan C, Zhang H, Wang L. Two-dimensional graphene analogues for biomedical applications. Chem Soc Rev. 2015;44 (9):2681-2701. doi:10.1039/C4CS00300D

22. Georgakilas V, Tiwari JN, Kemp KC, et al. Noncovalent functionalization of graphene and graphene oxide for energy materials, biosensing, catalytic, and biomedical applications. Chem Rev. 2016;116 (9):5464-5519. doi:10.1021/acs.chemrev.5b00620

23. Sun X, Liu Z, Welsher K, et al. Nano-graphene oxide for cellular imaging and drug delivery. Nano Res. 2008;1(3):203-212. doi:10.1007/s12274-008-8021-8

24. Yang K, Feng L, Shi X, Liu Z. Nano-graphene in biomedicine: theranostic applications. Chem Soc Rev. 2013;42(2):530-547. doi:10.1039/C2CS35342C

25. Shankla M, Aksimentiev A. Conformational transitions and stop-andgo nanopore transport of single-stranded DNA on charged graphene. Nat Commun. 2014;5:5171. doi:10.1038/ncomms6171

26. Boussif O, Lezoualc'h F, Zanta MA, et al. A versatile vector for gene and oligonucleotide transfer into cells in culture and in vivo: polyethylenimine. Proc Natl Acad Sci $U$ S A. 1995;92 (16):7297-7301. doi:10.1073/pnas.92.16.7297

27. Neu M, Fischer D, Kissel T. Recent advances in rational gene transfer vector design based on poly(ethylene imine) and its derivatives. $J$ Gene Med. 2005;7(8):992-1009. doi:10.1002/(ISSN)1521-2254

28. Choi HY, Lee TJ, Yang GM, et al. Efficient mRNA delivery with graphene oxide-polyethylenimine for generation of footprint-free human induced pluripotent stem cells. $J$ Control Release. 2016;235:222-235. doi:10.1016/j.jconrel.2016.06.007

29. Ma J, Liu R, Wang X, et al. Crucial role of lateral size for graphene oxide in activating macrophages and stimulating pro-inflammatory responses in cells and animals. ACS Nano. 2015;9(10):10498-10515. doi:10.1021/acsnano.5b04751

30. Chen GY, Meng CL, Lin KC, et al. Graphene oxide as a chemosensitizer: diverted autophagic flux, enhanced nuclear import, elevated necrosis and improved antitumor effects. Biomaterials. 2015;40:12-22. doi:10.1016/j.biomaterials.2014.11.034

31. Liu J, Cui L, Losic D. Graphene and graphene oxide as new nanocarriers for drug delivery applications. Acta Biomater. 2013;9 (12):9243-9257. doi:10.1016/j.actbio.2013.08.016

32. Tang Z, Wu H, Cort JR, et al. Constraint of DNA on functionalized graphene improves its biostability and specificity. Small. 2010;6 (11):1205-1209. doi:10.1002/smll.201000024

33. Chen B, Liu M, Zhang L, Huang J, Yao J, Zhang Z. Polyethylenimine-functionalized graphene oxide as an efficient gene delivery vector. J Mater Chem. 2011;21(21):7736-7741. doi:10.1039/ c1jm10341e

34. Tian X, Zeng G, Li X, Wu Z, Wang L. Cantharidin inhibits cell proliferation and promotes apoptosis in tongue squamous cell carcinoma through suppression of miR-214 and regulation of p53 and Bcl-2/Bax. Oncol Rep. 2015;33(6):3061-3068. doi:10.3892/or.2015. 3942

35. Futreal PA, Coin L, Marshall M, et al. A census of human cancer genes. Nat Rev Cancer. 2004;4(3):177-183. doi:10.1038/nrc1299

36. von Burstin J, Eser S, Paul MC, et al. E-cadherin regulates metastasis of pancreatic cancer in vivo and is suppressed by a SNAIL/HDAC1/ HDAC2 repressor complex. Gastroenterology. 2009;137(1):361-371, 371.e361-365. doi:10.1053/j.gastro.2009.04.004
37. Xu CX, Xu M, Tan L, et al. MicroRNA MiR-214 regulates ovarian cancer cell stemness by targeting p53/Nanog. J Biol Chem. 2016;291 (43):22851. doi:10.1074/jbc.A112.374611

38. Wang F, Lv P, Liu X, Zhu M, Qiu X. microRNA-214 enhances the invasion ability of breast cancer cells by targeting p53. Int $\mathrm{J} \mathrm{Mol}$ Med. 2015;35(5):1395-1402. doi:10.3892/ijmm.2015.2123

39. Wang YS, Wang YH, Xia HP, Zhou SW, Schmid-Bindert G, Zhou CC. MicroRNA-214 regulates the acquired resistance to gefitinib via the PTEN/AKT pathway in EGFR-mutant cell lines. Asian Pac J Cancer Prev. 2012;13(1):255-260. doi:10.7314/APJCP.2012. 13.1.255

40. Yang TS, Yang XH, Wang XD, Wang YL, Zhou B, Song ZS. MiR214 regulate gastric cancer cell proliferation, migration and invasion by targeting PTEN. Cancer Cell Int. 2013;13(1):68. doi:10.1186/ 1475-2867-13-68

41. Lee YR, Chen M, Pandolfi PP. The functions and regulation of the PTEN tumour suppressor: new modes and prospects. Nat Rev Mol Cell Biol. 2018;19:547-562. doi:10.1038/s41580-018-0015-0

42. Nakanishi A, Kitagishi Y, Ogura Y, Matsuda S. The tumor suppressor PTEN interacts with $\mathrm{p} 53$ in hereditary cancer (Review). Int J Oncol. 2014;44(6):1813-1819.

43. Freeman DJ, Li AG, Wei G, et al. PTEN tumor suppressor regulates p53 protein levels and activity through phosphatase-dependent and independent mechanisms. Cancer Cell. 2003;3(2):117-130. doi:10.1 016/S1535-6108(03)00021-7

44. Stambolic V, MacPherson D, Sas D, et al. Regulation of PTEN transcription by p53. Mol Cell. 2001;8(2):317-325. doi:10.1016/ S1097-2765(01)00323-9

45. Carracedo A, Pandolfi PP. The PTEN-PI3K pathway: of feedbacks and cross-talks. Oncogene. 2008;27(41):5527-5541. doi:10.1038/ onc. 2008.247

46. Zhao H, Feng H, Liu D, et al. Self-assembling monomeric nucleoside molecular nanoparticles loaded with 5-FU enhancing therapeutic efficacy against oral cancer. ACS Nano. 2015;9(10):9638-9651. doi:10.1021/acsnano.5b04520

47. Li J, Tan S, Kooger R, Zhang C, Zhang Y. MicroRNAs as novel biological targets for detection and regulation. Chem Soc Rev. 2014;43(2):506-517. doi:10.1039/C3CS60312A

48. Naldini L. Gene therapy returns to centre stage. Nature. 2015;526 (7573):351-360. doi:10.1038/nature 15818

49. Lennox KA, Behlke MA. Chemical modification and design of anti-miRNA oligonucleotides. Gene Ther. 2011;18(12):1111-1120. doi:10.1038/gt.2011.100

50. Chitkara D, Mittal A, Mahato RI. miRNAs in pancreatic cancer: therapeutic potential, delivery challenges and strategies. Adv Drug Deliv Rev. 2015;81:34-52. doi:10.1016/j.addr.2014.09.006

51. Liu J, Dong J, Zhang T, Peng Q. Graphene-based nanomaterials and their potentials in advanced drug delivery and cancer therapy. J Control Release. 2018;286:64-73. doi:10.1016/j.jconrel.2018.07.034

52. Duran N, Martinez DS, Silveira CP, et al. Graphene oxide: a carrier for pharmaceuticals and a scaffold for cell interactions. Curr Top Med Chem. 2015;15(4):309-327. doi:10.2174/1568026615666150108144217

53. Chung C, Kim YK, Shin D, Ryoo SR, Hong BH, Min DH. Biomedical applications of graphene and graphene oxide. Acc Chem Res. 2013;46(10):2211-2224. doi:10.1021/ar300159f

54. Kim H, Namgung R, Singha K, Oh IK, Kim WJ. Graphene oxide-polyethylenimine nanoconstruct as a gene delivery vector and bioimaging tool. Bioconjug Chem. 2011;22(12):2558-2567. doi:10. 1021/bc200397j

55. Yin D, Li Y, Lin H, et al. Functional graphene oxide as a plasmid-based Stat3 siRNA carrier inhibits mouse malignant melanoma growth in vivo. Nanotechnology. 2013;24(10):105102. doi:10.1088/0957-4484/24/10/105102

56. Penna E, Orso F, Taverna D. miR-214 as a key hub that controls cancer networks: small player, multiple functions. $J$ Invest Dermatol. 2015;135(4):960-969. doi:10.1038/jid.2014.479 
57. Zhang L, Lu Z, Zhao Q, Huang J, Shen H, Zhang Z. Enhanced chemotherapy efficacy by sequential delivery of siRNA and anticancer drugs using PEI-grafted graphene oxide. Small. 2011;7 (4):460-464. doi:10.1002/smll.201001522

58. Liu X, Ma D, Tang H, et al. Polyamidoamine dendrimer and oleic acid-functionalized graphene as biocompatible and efficient gene delivery vectors. ACS Appl Mater Interfaces. 2014;6(11):8173-8183. doi:10. 1021/am500812h

59. Perez-Martinez FC, Guerra J, Posadas I, Cena V. Barriers to non-viral vector-mediated gene delivery in the nervous system. Pharm Res. 2011;28(8):1843-1858. doi:10.1007/s11095-010-0364-7

60. Lv H, Zhang S, Wang B, Cui S, Yan J. Toxicity of cationic lipids and cationic polymers in gene delivery. J Control Release. 2006;114 (1):100-109. doi:10.1016/j.jconrel.2006.04.014

61. Dong H, Ding L, Yan F, Ji H, Ju H. The use of polyethylenimine-grafted graphene nanoribbon for cellular delivery of locked nucleic acid modified molecular beacon for recognition of microRNA. Biomaterials 2011;32(15):3875-3882. doi:10.1016/j.biomaterials.2011.02.001

62. Patel SC, Lee S, Lalwani G, Suhrland C, Chowdhury SM, Sitharaman B. Graphene-based platforms for cancer therapeutics. Ther Deliv. 2016;7(2):101-116. doi:10.4155/tde.15.93

63. Zhou JP, Gao ZL, Zhou ML, et al. Snail interacts with Id 2 in the regulation of TNF-alpha-induced cancer cell invasion and migration in OSCC. Am J Cancer Res. 2015;5(5):1680-1691.
64. Zhao D, Tang XF, Yang K, Liu JY, Ma XR. Over-expression of integrin-linked kinase correlates with aberrant expression of Snail, E-cadherin and $\mathrm{N}$-cadherin in oral squamous cell carcinoma: implications in tumor progression and metastasis. Clin Exp Metastasis. 2012;29(8):957-969. doi:10.1007/s10585-012-9485-1

65. Li YY, Zhou CX, Gao Y. Snail regulates the motility of oral cancer cells via RhoA/Cdc42/p-ERM pathway. Biochem Biophys Res Commun. 2014;452(3):490-496. doi:10.1016/j.bbrc.2014.08.110

66. Abraham AG, O'Neill E. PI3K/Akt-mediated regulation of p53 in cancer. Biochem Soc Trans. 2014;42(4):798-803. doi:10.1042/ BST20140070

67. Li AG, Piluso LG, Cai X, Wei G, Sellers WR, Liu X. Mechanistic insights into maintenance of high p53 acetylation by PTEN. Mol Cell. 2006;23(4):575-587. doi:10.1016/j.molcel.2006.06.028

68. Paez J, Sellers WR. PI3K/PTEN/AKT pathway. A critical mediator of oncogenic signaling. Cancer Treat Res. 2003;115:145-167.

69. Yang H, Kong W, He L, et al. MicroRNA expression profiling in human ovarian cancer: miR-214 induces cell survival and cisplatin resistance by targeting PTEN. Cancer Res. 2008;68(2):425-433. doi:10.1158/0008-5472.CAN-07-2488

70. Xin R, Bai F, Feng Y, et al. MicroRNA-214 promotes peritoneal metastasis through regulating PTEN negatively in gastric cancer. Clin Res Hepatol Gastroenterol. 2016;40(6):748-754. doi:10.1016/j. clinre.2016.05.006
International Journal of Nanomedicine

\section{Publish your work in this journal}

The International Journal of Nanomedicine is an international, peerreviewed journal focusing on the application of nanotechnology in diagnostics, therapeutics, and drug delivery systems throughout the biomedical field. This journal is indexed on PubMed Central, MedLine, CAS, SciSearch ${ }^{\circledR}$, Current Contents ${ }^{\circledR} /$ Clinical Medicine, $^{-}$

\section{Dovepress}

Journal Citation Reports/Science Edition, EMBase, Scopus and the Elsevier Bibliographic databases. The manuscript management system is completely online and includes a very quick and fair peer-review

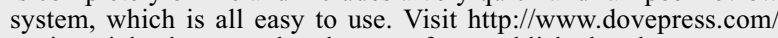
testimonials.php to read real quotes from published authors. 